Motrivivência v. 26, n. 43, p. 183-197, dezembro/2014

\title{
RELAÇÕES ENTRE BELEZA E SAÚDE FEMININA: um olhar a partir da perspectiva de professoras de Educação Física
}

\author{
Angélica Teixeira da Silva Leitzke' \\ Tadeu João Ribeiro Baptista² \\ Ana Márcia Silva ${ }^{3}$
}

\begin{abstract}
RESUMO
Pesquisa qualitativa do tipo descritiva objetivou discutir possíveis influências da Indústria Cultural bem como da atual lógica de consumo nas relações entre beleza e saúde feminina a partir de pesquisa realizada com 20 professoras de Educação Física da rede pública de ensino de Goiânia/GO. Os dados indicam uma aproximação entre os conceitos de beleza e saúde e marcas de um processo histórico de fetichização e reificação do corpo feminino. É possível perceber, porém, movimentos de contradição e resistência aos padrões impostos.
\end{abstract}

Palavra-chave: Corpo; Beleza; Saúde; Mulher; Indústria Cultural

1 Mestranda em Educação Física. UFPEL, Pelotas/Rio Grande do Sul, Brasil.

E-mail: angel.lilica@hotmail.com

2 Doutor em Educação. Docente da Faculdade de Educação Física/UFG. Goiânia/Goiás, Brasil.

E-mail: tadeujrbaptista@yahoo.com.br

3 Doutora em Ciências Humanas. Docente da Faculdade de Educação Física/UFG. Goiânia/Goiás, Brasil.

E-mail: amarciasi@gmail.com 


\section{INTRODUÇÃO}

O corpo tem se tornado, concomitantemente, palco e vitrine de intervenções diversas com vistas a sua aceitação social, sobretudo desde a segunda metade do século XX (DUBY, 1991). Coerente com sua condição de produto histórico, constantemente se modifica a forma como o corpo é visto, percebido, concretizado ou mesmo constituído (MEYER, 2003), com uma gradativa aproximação entre as percepções de saúde e beleza trazendo implicações que não têm sido problematizadas suficientemente pela literatura acadêmica.

Instâncias como a escola, a mídia, as relações familiares, religiosas, trabalhistas são importantes influências a constituição do sujeito. Segundo Goellner (2003, p. 29):

[...] diferentes marcas se incorporam ao corpo a partir de distintos processos educativos presentes na escola, mas não apenas nela, visto que há sempre várias pedagogias em circulação. Filmes, músicas, revistas e livros, imagens propagandas são também locais pedagógicos que estão o tempo todo a dizer de nós, sejam pelo que exibem ou pelo que ocultam. Dizem também de nossos corpos e, por vezes, de forma tão sutil que nem mesmo percebemos o quanto somos capturadas/os e produzidas/os pelo que lá se diz.

Na mesma lógica de múltiplas determinações caminha a percepção de beleza feminina. Uma percepção que tem se apresentando mutável a partir de inúmeros processos e relações histórico-sociais, tais como as influências da Indústria Cultural (ADORNO; HORKHEIMER, 1985) e da lógica de consumo. Observa-se também um gradual estreitamento entre as relações de beleza e saúde feminina - e também masculina -, como mencionado acima (ALMEIDA, 2006; LOVISOLO, 2006; DAMICO; MEYER, 2006; SILVA; SILVA; BAPTISTA, 2012).

Este artigo discute âmbitos da influência da Indústria Cultural e da lógica de consumo nas relações entre beleza e saúde feminina a partir de uma análise das falas de mulheres de diferentes faixas etárias, professoras de Educação Física da rede pública de educação de Goiânia/GO. Neste sentido, primeiramente discutiremos acerca da Indústria Cultural e suas ramificações, bem como a respeito da lógica de consumo e dos mecanismos para a criação do "desejo" pelo "corpo perfeito". Apresentaremos posteriormente os meandros metodológicos da pesquisa e destacaremos algumas características de nossas pesquisadas. Por fim, realizaremos a análise dos dados a partir do referencial teórico.

As relações entre beleza e saúde aqui discutidas, influenciadas pela lógica de consumo e pela Indústria Cultural, são temáticas muito exploradas no âmbito acadêmico. Discute-se a grande veiculação e exposição de imagens de corpos magros, jovens, belos, felizes e "saudáveis", em prol da criação de ideais de beleza e venda da "melhor receita" para promoção e/ou manutenção da saúde (ARAÚJO, 2008; BEZERRA, 2008; ALMEIDA et al, 2006; DAMICO; MEYER, 2006; LOVISOLO, 2006; VIGARELLO, 2006; ROSA, 2005).

Percebe-se que, de alguma forma, estes ideais de beleza largamente veiculados são reforçados também nas práticas vinculadas a Educação Física:

[...] Esse ideal de beleza é facilmente identificado nas práticas da Educação Física, que também tem se empenhado 
ao longo da história em treinar o corpo para se encaixar em uma determinada métrica. [...] A educação física, nesse contexto, canonizou modelos de beleza, excluindo tudo o que fugisse a esse tipo de controle, sempre em prol da construção de corpo forte, ágil, belo no sentido clássico [...]. (BEZERRA, 2008, p. 109).

É tarefa acadêmica compreender os processos históricos de formação das concepções de corpo atuais, bem como estes se vinculam com concepções de saúde e perspectivas de beleza, a fim de não nos tornarmos mais um agente "naturalizador" de preceitos contraditórios incutidos pela Indústria Cultural a favor da criação de necessidades de consumo.

Nessa direção, concordamos com Goellner (2003, p. 28) sobre a necessidade de se (re)pensar o corpo:

Pensar o corpo como algo produzido na e pela cultura é, um desafio e uma necessidade. Um desafio porque rompe, de certa forma, com o olhar naturalista sobre o qual muitas vezes o corpo é observado, explicado, classificado e tratado. Uma necessidade porque ao desnaturalizá-lo revela, sobretudo que o corpo é histórico. [...] o corpo é uma construção sobre a qual são conferidas diferentes marcas em diferentes tempos, espaços, conjunturas econômica, grupos sociais, étnicos, etc.

\section{O corpo-modelo: influências da Indústria Cultural na criação do desejo}

Atualmente, mecanismos sociais de grande influência na vida cotidiana diluem as possibilidades de questionamentos das necessidades impostas pela ordem econômico-social Capitalista, e em certa medida, nos torna veículos de disseminação destes preceitos e sua lógica consumista. Fala-se da Indústria Cultural:

A "indústria cultural" pode ser entendida como um instrumento de pressão da sociedade sobre o indivíduo através da utilização de elementos culturais que se tornam acessíveis pelo cinema, pela televisão e por outros meios de comunicação de massa. Esses são utilizados como formas de cooptarem os indivíduos para uma atuação de acordo com os interesses e as necessidades do modo de produção, fazendo a lógica industrial prevalecer [...]. (BAPTISTA, 2001, p. 75).

A indústria cultural, na compreensão de Adorno e Horkheimer (1985), é responsável pela disseminação de certa lógica social e pela perda do esclarecimento da população:

O segmento sobre a "indústria cultural" mostra a regressão do esclarecimento à ideologia, que encontra no cinema e no rádio sua expressão mais influente. $\mathrm{O}$ esclarecimento consiste aí, sobretudo, no cálculo da eficácia e na técnica de produção e difusão. Em conformidade com seu verdadeiro conteúdo, a ideologia se esgota na idolatria daquilo que existe e do poder pelo qual a técnica é controlada. No tratamento desta contradição, a indústria cultural é levada mais a sério do que gostaria. (ADORNO; HORKHEIMER, 1985, p. 16)

A Indústria Cultural tem assim uma função importante no desenvolvimento de um modelo de corpo com características específicas. Para facilitar este controle ela se ramifica em outros mecanismos denominados Indústria da Beleza e Indústria do Emagrecimento (ALMEIDA et al, 2006) promovendo um intenso movimento de criação de desejos - fetiche - pelo corpo 
mais belo, encontrando na mídia e na publicidade instrumentos propícios para incuti-los e difundi-los:

Quando se discute a publicidade, algumas idéias logo surgem, e entre elas a de sedução, e a de manipulação, ou seja, a publicidade como um eficiente recurso para, após a identificação de prováveis necessidades, ou desejos dos indivíduos, servir como uma ferramenta para influenciar seus receptores a adquirirem produtos, necessitando ou não deles. (ARAÚJO, 2008, p. 1).

A larga veiculação de imagens "agradáveis" de corpos magros, jovens e sorridentes, incute o desejo pelo que não se tem e a não aceitação pelo que se é. Desta forma, o "consumidor" necessita comprar e possuir o mesmo corpo de sua referência:

[...] o grande padrão de referência são as pessoas que aparecem na mídia, como os artistas, [...] porque todos eles, ao menos os que são considerados belos, são magros, cria-se uma certa tendência para considerá-los os modelos ideais. Assim, não é difícil encontrar-se pessoas pelas ruas que sigam as orientações de dieta, de exercícios e outras dicas de seus artistas de preferência (ALMEIDA et al, 2006, p. 795).

O corpo exposto e "vendido" como um objeto é ilusório na medida em que "[...] o [corpo] ideal que ele [consumidor] almeja dificilmente será alcançado, em virtude dos truques utilizados em anúncios publicitários (photoshop, dublês, maquiagem...)" (ARAÚJO, 2008, p. 1). Adorno e Horkheimer (1985) comentam que a Indústria Cultural:

[...] como invocação de seu próprio caráter comercial, de sua profissão de uma verdade atenuada, há muito se tornou uma evasiva com a qual ela tenta se furtar à responsabilidade pela mentira que difunde, nossa análise atém-se à pretensão, objetivamente inerente aos produtos, de serem obras estéticas e, por isso mesmo, uma configuração da verdade. Ela revela, na nulidade dessa pretensão, o caráter maligno do social. O segmento sobre a indústria cultural é ainda mais fragmentário que os outros. (ADORNO; HORKHEIMER, 1985, p. 16)

Para a mulher, talvez este ideal de beleza seja mais fortemente veiculado e difundido, haja vista a grande exposição dos corpos femininos atualmente. Essa padronização do corpo da mulher é reforçada nestes meios que corroboram para a construção da identidade - inclusive corporal - feminina:

[...] vivemos um tempo em que meios de comunicação de massa como revistas, jornais e programas de televisão produzem e veiculam toda uma discursividade sobre e para o corpo, contemplando, entre outras coisas, modos de vestir, comer, exercitar-se, maquiar-se ou divertir-se (DAMICO; MEYER, 2006, p. 104).

Parece haver efetivamente uma "ditadura" do que se deve fazer, vestir ou ser. As mulheres são incessantemente bombardeadas e educadas para adequação aos padrões de beleza impostos. A Indústria Cultural cuida de camuflar suas intenções com mensagens de promessas de maior auto-estima, saúde e realização pessoal (ROSA, 2005).

Com a liberação feminina, novos horizontes foram abertos ao cotidiano de mulheres em diferentes realidades sociais. Elas passaram a ocupar espaços mais relevantes no mercado de trabalho. Seu poder aquisitivo aumentou proporcionalmente a 
sua exposição social. Para Rosa (2005), as "fórmulas" de beleza apresentam-se como uma terceira jornada de trabalho às muIheres que, além do trabalho remunerado, submetem-se também ao trabalho de casa e as estratégias de embelezamento.

Obviamente, é necessário pensar em um processo dialético de criação/ apropriação destes processos. As influências da Indústria Cultural na formação de concepções femininas de corpo e beleza não anulam a subjetividade de cada mulher:

Isso não quer dizer que quaisquer desses discursos [veiculados pela Indústria Cultural] sejam causas em si do culto contemporâneo ao corpo, mas que é neles que se constituem condições de possibilidades para que as jovens sejam posicionadas - e se posicionem - como mais próximas ou mais distantes das normas de beleza e saúde socialmente sancionadas. (DAMICO; MEYER, 2006, p. 106).

Cabe ressaltar que o modelo de corpo disseminado não atinge a todos. Ainda existem focos de resistência, mesmo que alguns sejam não intencionais. Para Baptista (2013) este é o caso de pessoas consideradas com sobrepeso ou obesidade. Porém, é indiscutível a implicação deste padrão imposto, vez que a busca ou a fuga destes traz angústias a mulheres de diversas classes sociais.

No início do século XX o excesso de gordura corporal já começa a ser tomado enquanto anomalia, relacionada a doenças múltiplas. Segundo Vigarello (2006), quadros associativos são divulgados em revistas femininas de moda, o que incentiva o surgimento de um ideal de magreza, justificada pela busca da saúde, não possível por um corpo avantajado.
Resultados deste "emagrecimento" do corpo tido como ideal também são percebidos por Silva (2001). Estudos acerca de concursos de beleza femininos do século $X X$ explicitam que no decorrer de 80 anos houve uma diminuição de $2,5 \mathrm{~cm}$ na silhueta feminina "ideal", evidenciando o processo de "generalização" de uma "estética da magreza".

Todas estas influências, amplamente divulgadas no contexto atual, a mulheres de diversas classes e idades, podem ser identificadas ao analisarmos os discursos de nossas pesquisadas, ainda que possamos perceber também movimentos de superação dos paradigmas impostos.

\section{As mulheres que olhamos: De onde vem? Quem são?}

Este artigo resulta de pesquisa anteriormente realizada em Programa de Iniciação Científica do Conselho Nacional de Pesquisa (PIBIC/CNPq), junto a Universidade Federal de Goiás, entre os anos de 2009 a 2011, financiado pela Fundação de Amparo à Pesquisa do Estado de Goiás (FAPEG) e aprovado pelo comitê de Ética em Pesquisa com Seres Humanos da Universidade Federal de Goiás, no 158/08.

De metodologia qualitativa, desenvolvido com apoio de questionário com perguntas abertas e fechadas, teve como sujeitos da pesquisa inicial 34 professores de Educação Física (20 mulheres e 14 homens) atuantes em 21 escolas públicas selecionadas a partir das doze regiões administrativas da cidade de Goiânia/ GO. Para os fins desta análise específica, realizou-se um recorte da amostra, mantendo apenas os 20 questionários respondidos 
pelas mulheres. Todos os pesquisados assinaram Termo de Compromisso Livre e Esclarecido (TCLE).

Para preservar a identidade dos participantes, convencionou-se chamá-los apenas por "P.N" onde "P" significa professor(a) e "N" um número de 1 a 34, estipulado aleatoriamente a cada questionário, incluindo os 14 questionários respondidos por homens na primeira fase desta pesquisa, os quais foram analisados em outro momento (SILVA; SILVA; BAPTISTA, 2012).

As pesquisadas são mulheres de uma extensa faixa etária (dos 21 aos 50 anos) e de rendas familiares diversas (7 mulheres recebem de 3 a 5 salários mínimos; 6 recebem de 5 a 7 salários mínimos e 5 obtêm entre 8 a 10 salários mínimos. Duas não informaram sua renda). A maioria possui imóvel próprio (14 pesquisadas) e automóvel (13 mulheres), também a maioria possui acesso à internet (19 professoras). Dentre as pesquisadas, 16 relataram possuir pós-graduação em uma das seguintes áreas: Educação Física Escolar, Fisiologia, Atividade Física, Saúde, Métodos de Ensino, Educação Física Adaptada, Direitos Humanos e Educação.

\section{O corpo do qual se fala, o corpo que se deseja: relações percebidas entre saúde e beleza}

Indagamos acerca da auto-percepção corporal de nossas pesquisadas, questionando: "Quando você se olha no espelho se vê:" As alternativas propostas foram: "obeso(a); acima do peso; esbelto(a); magro(a); muito magro(a)". Respondendo a este questionamento, 8 mulheres declararam se enxergar acima do peso; igualmente 8 se enxergam como esbeltas; 3 professoras dizem se ver como pessoas magras e apenas uma pesquisada diz se ver como obesa.

Estar acima do peso tido como "ideal" parece ser uma preocupação considerável de mulheres de todas as faixas etárias. Estas mulheres, acima do peso "ideal", têm sido tomadas pela Indústria Cultural enquanto um rico e crescente mercado. Cada vez mais produtos e discursos são criados para abarcar suas "necessidades":

[...] a Indústria Cultural vai se ocupar com estas pessoas. Se, por um lado, ela tem que combatê-las, de acordo com os interesses na saúde dos sistemas, por outro, este é um público que, como consumidor, deve ser bem tratado e ter à sua disposição diferentes produtos que o atendam, como roupas, dietas, spas, sapatos, móveis especiais e que possam suportar o seu peso. (ALMEIDA et al, 2006, p. 797).

Paradoxalmente ao combate pelo extermínio da gordura, nociva a vida "saudável", há também o movimento de criação de especialidades "adaptadas", que propiciem conforto a mulheres "gordinhas", afinal, elas merecem, desde que possam pagar por isso. Indiscutivelmente há um padrão imposto nas duas situações, já que um é o ideal, e o outro é o adaptável ao padrão da "estética da magreza".

Incute-se a necessidade de consumir a academia, a dieta, o emagrecedor que seja

4 Destacaremos aqui todas as "P.Ns" utilizadas para os fins desta análise: P.4, P.5, P.6, P.7, P.8, P.11, P.12, P.13, P.14, P.16, P.17, P.22, P.23, P.26, P.27, P.28, P.30, P.31, P.33, P.34. 
considerado melhor, para o resultado em busca da "estética da magreza". Enquanto não se atinge o objetivo, há a necessidade de se vestir bem, calçar sapatos confortáveis para sua estrutura corporal, se consumir o que há de mais "adequado".

Desta forma a ordem do consumo impera nesta relação, não havendo a mesma oportunidade para todos:

[...] os bens e benefícios prometidos pela indústria da beleza (e evidentemente da indústria cultural) não estão acessíveis a todas as pessoas, mas apenas para aquelas que podem pagar por isso, visto que os diferentes produtos elaborados são apropriados para consumos específicos. (ALMEIDA et al, 2006, p. 794).

Portanto, a Indústria Cultural nos enreda em um ciclo que parte da imagem sedutora do corpo esbelto, criando a necessidade de consumo. Mesmo às mulheres que se apresentam como magras e esbeltas em nossa pesquisa, pode-se dizer, haveria a necessidade da manutenção da aparência, alcançada através do consumo de produtos para esta finalidade.

Sobre estas questões referentes aos cuidados com o corpo e suas relações com a lógica de consumo, Nóbrega (2001, p. 2) destaca:

Featherstone et alii (1996) analisam essa emergência da cultura do consumo a partir de dois pilares básicos, a saber: a manutenção e a aparência. A aparência relaciona-se com as imagens de corpo, a preocupação com o "visual". A manutenção relaciona-se com as rotinas de adequação aos valores e padrões de consumo divulgados pelas próprias imagens. Aparência e manutenção são categorias que se retroalimentam, na lógica fantasiosa do consumo.
O corpo belo, esbelto, referência dos padrões atuais, não é almejado desinteressadamente. É preciso expor este corpo. O corpo, como ressalta Nóbrega (2001, p. 01-02) é agora tomado por uma

[...] nova cultura do consumo [que] se estabelece a partir da imagem do corpo bonito, sexualmente disponível e associado ao hedonismo, ao lazer e à exibição, enfatizando a importância da aparência e do visual. Essas imagens de corpo são divulgadas pelos meios de comunicação de massa e mídia eletrônica, exigindo toda uma rotina de exercícios, dietas, cosméticos, terapias, entre outras preocupações com a imagem e a auto-expressão, uma exposição sem limites do corpo (corpo-outdoor).

$\mathrm{Na}$ atualidade parece não haver como desvincular beleza de magreza. Estas duas categorias imbricam-se nos discursos que dão subsídios à lógica de consumo do "corpo-modelo/objeto". Na busca por esta beleza, a responsabilidade individual parece imperar. Instaura-se uma perspectiva de que cada indivíduo pode ter acesso ao melhor, desde que busque isto (LOVISOLO, 2006).

Há vinculação da imagem do indivíduo gordinho à figura de uma pessoa desleixada, que não se propõe a realizar exercícios nem a cuidar de sua alimentação com mais zelo (ALMEIDA et al, 2006). Esta desvalorização da imagem das pessoas obesas, pode se relacionar com mais um processo de inculcação do consumo de práticas para a magreza, oferecidas largamente na atualidade, impregnando o discurso da necessidade do consumo de itens adequados ao alcance de um peso "aceitável".

Questionamos às nossas pesquisadas: "Você tem algum ideal de beleza"? 9 professoras assumiram possuir um modelo 
de corpo perfeito, enquanto 10 relataram não se importar com os padrões pré-estabelecidos, ainda que em outro momento, algumas destas tenham descrito estratégias variadas para atingir algum ideal de beleza, e também apontem personalidades públicas como referenciais desse padrão.

As várias representações sociais difundidas pela Indústria Cultural são primordiais neste processo de inculcação/invenção de ideais de beleza feminina, instituem um desejo, uma energia fetichizante sedutora acerca do corpo/objeto almejado.

Esta influência midiática na criação de modelos aparece, podemos dizer, quando questionamos quais personalidades são identificadas por nossas pesquisadas como modelos de beleza através da pergunta: "Você identifica alguma pessoa pública (atleta, atriz/ator, cantor/a, modelo, etc.) que corresponda ao seu ideal de beleza? Quem?". As personalidades destacadas foram Jennifer Lopez, Malu Mader, Fernanda Lima, Daniele Sousa e Maurren Maggi.

As personalidades destacadas por nossas pesquisadas tem projeção na sociedade atual, são estrelas de televisão, e como tal possuem determinado prestígio (NEPOMUCENO, 2010). Têm, via de regra, corpos adequados ao padrão da "estética da magreza", oferecidos nos outdoors da Indústria da Beleza e do Emagrecimento (ALMEIDA et al, 2006).

Figuras públicas são ótimos meios de difusão do ideário de corpo vigente.
Baptista, Araújo e Brito (2009, p. 1079) destacam:

\begin{abstract}
A beleza passa a ser aspirada de forma tão intensa, que só é valorizada a muIher que se parece com as estrelas da televisão. Aquelas mulheres altas, magras, com lindos cabelos e sempre bem vestidas. A mídia dita a moda e gera lucros para o mercado da beleza, onde todas terão que consumir para se integrarem numa sociedade em que a aparência importa mais do que o ser [...].
\end{abstract}

Neste sentido, ter um corpo de atriz é um objetivo eventualmente almejado por mulheres de qualquer classe social e não são poucos os métodos para atingir tais objetivos. A Indústria da Beleza e do Emagrecimento oferecem vários "planos" de "reeducação" alimentar e de exercícios físicos, remédios e intervenções cirúrgicas, tudo em busca do "corpo ideal" que apresenta um perfil magro e jovem (ALMEIDA et al, 2006).

A similaridade corporal com personalidades públicas carrega em si um status positivo, um prazer, o qual é tomado como o referido "bem-estar" tão destacado nas propagandas de venda deste corpo/objeto, mesmo que para isso haja a necessidade de outros sacrifícios:

[...] O prazer do JUBESA ${ }^{5}$, no reconhecimento dos outros, do espelho e da auto-percepção, implica na abstenção de outros prazeres, e disso decorre a insistência dos interventores da atividade física, dos educadores físicos, para que

5 O modelo JUBESA é um conceito trabalhado por Lovisolo (2006) a partir de um jogo com as palavras Juventude, Beleza e Saúde. 
as práticas estejam associadas ao prazer ou a ele conduzam. (LOVISOLO, 2006, p. 161-162).

A necessidade criada às mulheres de todas as classes sociais de encontrar o "corpo perfeito" perpassa a disciplina do corpo e das vontades. Neste sentido, a mulher deve se ater a "uma vida saudável" limitando suas práticas corporais, sua alimentação e seu estilo de vida ao modelo proposto. Em casos extremos há um vício, uma dependência vinculada à busca da perfeição; um paradoxo que Lovisolo (2006, p. 168-169) destaca ao tecer algumas críticas acerca do padrão JUBESA:

[...] à dedicação exclusiva ou obsessiva ao modelo que provocaria efeitos colaterais negativos: abandono de outras orientações valiosas e a criação de compulsão, anorexia, culpa, auto-centramento, entre outros. [...] A pessoa pode ficar viciada no modelo, concentrando nele toda a sua libido. Viciado, então, em 'procurar saúde' ou o padrão de beleza ou à juventude.

Este é um paradoxo considerável ao se analisar a desenfreada busca pela beleza, disfarçada pelo discurso da saúde. Os excessos, o vício e a concentração da libido são marcadores de processos de não-saúde imbricados na busca pelo corpo/objeto perfeito. Ainda para Lovisolo (2006, p. 169), a busca parece incessante, afinal, o mercado sempre reformula seus métodos para não perder seus "clientes": "[...] sempre é possível fazer um novo exame, ingerir mais uma droga protetora, usar mais um creme, ficar mais tempo na academia, tornar o regime mais vigoroso, perder mais uns gramas de peso corporal ou de gordurinhas localizadas [...]".
Se há o discurso, embasado em comprovações científicas de que a atividade física faz bem a saúde por que a necessidade incessante da criação de cada vez mais desejo sobre as práticas de exercícios físicos? "[...] se acreditamos que a atividade física faz bem à saúde, e se desejamos conservá-la (a saúde), então, deveríamos nos dedicar a sua prática. O "dever ser" da prática precisaria resultar, quase que "naturalmente" da junção da crença e do desejo" (LOVISOLO, 2006, p. 159).

Tem-se o desejo pelo bem-estar trago pelo corpo perfeito, e sua aceitação na sociedade atual. É esta uma das configurações estabelecidas para o fetiche do corpo, pois, o fetiche é o valor fantasmagórico e arbitrário dado a uma mercadoria (MARX, 2011). Neste caso, o corpo é a mercadoria que deve expressar o seu valor por meio da dimensão da saúde e da estética, mesmo que estes sejam falsos. Afinal, o fetiche não se dá obrigatoriamente pelo cumprimento das promessas realizadas.

No contexto atual, parece difícil à mulher resistir às propagandas de produtos que prometem a beleza que almeja. Para além de um simples "bem-estar" adquirido, existem vários sentidos simbólicos. Não por acaso, a beleza comercializada é expressão das classes sociais dominantes. Na cultura contemporânea, "[...] os diferentes grupos sociais se distinguem uns dos outros não só pela posse de bens materiais, mas pelas suas formas corporais, pela sua conduta e modo de expressar-se." (LUPTON, 2000, p. 22, apud DAMICO; MEYER, 2006, p. 106).

Mas afinal, o que é tido como belo por nossas pesquisadas? Questionou-se a elas: "Em sua opinião, quais as características de uma pessoa bonita?" Percebe-se nas falas resistências conscientes ou inconscientes 
a lógica da aparência, sendo valorizadas e enfatizadas algumas características subjetivas enquanto sinalizadores de uma beleza. Segundo a professora P.7: "As características são: amor próprio, auto-estima positiva; que não transfere seus problemas p/ os outros, etc.", características que figuram claramente em um âmbito mais subjetivo. Outra professora (P.30) destaca que bela é: "Uma pessoa arrumada, educada, humilde", mais uma afirma que bela é: "Uma pessoa que se sente bem com a sua imagem reflete um 'brilho' no olhar." (P.16). Mais uma relata:

Seria hipocrisia não ressaltar elementos exteriores, pois qualquer grupo estabelece um pré-julgamento, aquilo que se mostra inicialmente diferente da minha realidade 'sairia' do padrão de beleza mas diante de um diálogo a beleza interior pode ser evidenciada. Cada grupo estabelece seu padrão. (P.6).

Destacamos ainda o discurso das professoras P.25 e P.11 respectivamente: "Carismática, sociável, educada e que se cuide em todos os aspectos, tanto psicologicamente quanto fisicamente" e; "Uma pessoa saudável, tranqüila, sem exagero na preocupação com a aparência mas que se cuida, com sorriso".

Ainda que as declarações exprimam marcas de uma concepção de beleza subjetiva que claramente procura uma superação dos ideais pré-dispostos, não podemos deixar de considerar ainda haver traços do modelo de beleza veiculado pela Indústria Cultural. Existe uma tensão entre a resistência demonstrada pelos aspectos subjetivos e a submissão à lógica da Indústria Cultural por meio das referências adotadas para o belo e a saúde.
Os discursos, em certa medida, exprimem uma percepção de beleza imbricada à de saúde quando uma terminologia parece se equiparar a outra. Sobre estes aspectos de correlações entre beleza e saúde, Lovisolo (2006, p. 163) destaca: “[...] O recurso ao estético, à beleza e juventude, continua sendo relevante, ainda quando se trata de atingir resultados em termos de saúde. Sobretudo, se considerarmos que cuidar de si, adornar-se, embelezar-se, parece ser uma tendência muito antiga. [...]".

A saúde parece-nos estar intrinsecamente ligada a um processo de "embelezamento" que viria para legitimar ideais veiculados na atualidade pela mídia e pelas relações pessoais como um todo, que permeiam e são permeados pela lógica de consumo; processos relacionados com a reificação do corpo feminino, que abarcariam grande parte da população como nossas pesquisadas, professoras de Educação Física formadas há pouco tempo, muitas com estudos de pós-graduação. Neste caso, a reificação é a expressão da coisificação do ser humano e de sua consciência. De acordo com Lukács (2003):

[...] quando a atividade do homem se objetiva em relação a ele, torna-se uma mercadoria que é submetida à objetividade estranha aos homens, de leis sociais naturais, e deve executar seus movimentos de maneira tão independentes dos homens como qualquer bem destinado à satisfação de necessidades que se tornou artigo de consumo. (LUKÁCS, 2003, p. 199-200)

Nesta perspectiva, podemos identificar a ideia da reificação atrelada à lógica do fetiche do corpo. Desse modo, a busca pelo fetiche do corpo acaba por converter o próprio corpo em uma coisa, para a qual, a 
consciência do próprio corpo não identifica como humano.

Destacamos outros relatos. Características de beleza seriam: "Apresentar-se bem com saúde" (P.14), ou ainda: "Corpo em forma, saúde" (P. 34). Uma professora afirma: "A beleza física é quase insignificante mas nem obesa e nem magrela" (P.23).

Cabe destacar que recorre em algumas falas os cuidados com o cabelo e a pele enquanto marcadores de uma beleza: "Fisicamente: Estar com peso normal, cabelo e pele bem cuidados, saúde boa. Emocionalmente: equilibrada e de bem com a vida" (P.33), "[...] as características raciais, os traços, o corpo esbelto, cabelos cuidados, na verdade depende da simpatia da pessoa. $\mathrm{Na}$ verdade não tenho um ideal de beleza [...]" (P.26). Outra descreve: "A beleza vem de dentro para fora. Com certeza a paz de espírito faz com que tudo em seu organismo fique bem (pele, cabelos, etc.)" (P.4).

Para Baptista, Araújo e Brito (2009) a apresentação dos cabelos é igualmente uma marca de uma beleza elitizada, exibida por atrizes e outras personalidades públicas, de determinada forma, e não de outra. Via de regra, os cabelos exibidos - e vendidos devem ser lisos e esvoaçantes para serem bonitos. A pele bem cuidada sempre jovem e livre de manchas, também é marca de um padrão de beleza firmado na juventude e na saúde (LOVISOLO, 2006).

Diversas estratégias podem ser traçadas para se atingir e/ou manter o corpo idealizado. Para verificar quais seriam estas estratégias por parte de nossas pesquisadas, fizemos uma última pergunta: "Você faz algo para manter-se ou atingir este ideal de beleza?". As respostas, pode-se dizer, ecoam também em direção de uma assimilação entre beleza e saúde.
Estratégias de exercitação corporal e de cuidado com a alimentação são muito destacadas pelas pesquisadas para manter ou atingir seu ideal de beleza. Elas relatam: "Caminhada" (P.12); "Nem sempre, mas pratico esporte, principalmente voleibol" (P.30); "Sempre fiz, porém no momento estou com dificuldades para organizar meus horários." (P.5); "Procuro me alimentar corretamente, pratico exercício físico regularmente, cuido da minha pele e cabelo, cuido da minha vida espiritual e mantenho o equilíbrio" (P.33). A professora P.11 relata: "[...] Faço atividade física regular me preocupo com minha alimentação.". Outra pesquisada: "Não. Faço o que penso que todos deviam fazer que é comer bem (envolvendo os nutrientes necessários), faço caminhada, não fumo e tenho lazer." (P.4). Por fim mais uma afirma: "Tento me manter em peso saudável com aparência agradável a mim sem ficar preso a um ideal fechado" (P.14).

Estas estratégias são largamente veiculadas pela Indústria da Beleza e do Emagrecimento como eficientes na busca de um resultado materializado em um corpo/objeto perfeito, desejado e "saudável" (ALMEIDA et al, 2006). O processo de interposição e controle do corpo colabora para a reificação humana, tanto no sentido de sua transformação em objeto vendido e consumido, quanto no sentido de sua desnaturalização:

[...] é sem dúvida interessante o processo de desnaturalização que o corpo vem sofrendo em busca da imortalidade, da eterna juventude, da beleza perfeita, e nesse percurso são inúmeras as técnicas [...]: são os regimes alimentares (que têm levado à morte até mesmo crianças que já sofreram com o poder 
dos discursos sociais), as indústrias da cirurgia estética (a garantia da beleza com rapidez e comodidade). Aqui abrimos um paralelo para os modismos: é inacreditável a quantidade [...] de óbitos de jovens que morrem de fome [...] por não quererem comer para não engordar (SOARES; FRAGA, 2003 apud BEZERRA, 2008, p. 109-110).

O Mercado abarca todas as situações com alternativas pertinentes. Mulheres com dia cheio por sua rotina de trabalho têm opções entre dietas e exercícios adaptados ao tempo livre. A vida ativa se impõe quase como obrigatoriedade para atingir a beleza ideal: "[...] Temos que sublimar, mediante a atividade, o instinto do sedentarismo!" (LOVISOLO, 2006, p. 161).

Podemos dizer que as estratégias para se atingir e/ou manter um ideal de beleza, expressas pelas professoras parecem ir ao encontro da adequação às propostas da lógica de consumo:

Para a cultura de consumo, o corpo é veículo de prazer, estando associado a imagens idealizadas de juventude, saúde, aptidão e beleza, que favorecem a expansão da indústria da moda, cosméticos, academias de ginástica e afins. A manutenção, terminologia que indica a popularização da metáfora do corpo-máquina, demanda a monitoragem do atual estado da performance corporal, envolvendo a medicina preventiva, a educação para a saúde e o fitness. (NOBREGA, 2001, p. 2).

Desta forma, a hipervalorização do corpo é aspecto precioso a Indústria Cultural e revestir este processo pelo discurso da saúde é extremamente interessante. Uma última pesquisada ressalta: "Cuido da saú$d e^{\prime \prime}($ P.26).

\section{CONSIDERAÇÕES FINAIS}

O processo de aproximação entre os conceitos de beleza e saúde parecem frequentes no imaginário e discurso de muIheres na realidade atual, fruto de um processo histórico de inculcação de preceitos acerca de ideais de corpo e beleza advindos das classes dominantes e seus interesses. Não por acaso, as personalidades citadas por nossas pesquisadas enquanto modelo corpo almejado são pessoas jovens, de pele clara, magras, representantes de uma beleza elitizada, apenas encontrada quando o "consumidor" possui meios financeiros para adquiri-la. Porém, não apenas as condições financeiras influenciam na obtenção do chamado "corpo ideal". É necessário disciplina para manter as estafantes rotinas de exercícios e embelezamentos, que para a mulher, se traduzem quase como uma terceira rotina de trabalho.

Nos relatos dessas professoras podemos perceber inúmeros discursos que caminham claramente para a superação de ideais impostos pela Indústria Cultural, resultado esperado, já que as mulheres as quais tratamos nesta pesquisa possuem uma formação que as aproximaria de uma discussão crítica de corpo. Ainda assim, percebem-se marcas de um processo de reificação do corpo feminino, bem como algumas assimilações entre os conceitos de beleza e saúde, possíveis influências da Indústria Cultural e sua lógica de consumo e "venda do corpo". É neste sentido que o modelo de estetização da saúde se faz complexo e permeado de contradições, revestido por ideais de consumo, culminando em mais um processo desencadeador de realidades reificantes. 
A busca pelo corpo perfeito, a exposição do corpo feminino, a desvalorização humana, não pode ser vista como algo natural em nossa sociedade. Para nós, professores de Educação Física, esses conhecimentos se fazem extremamente necessários para que não nos tornemos mais um agente "naturalizador" das relações contraditórias da contemporaneidade.

\section{REFERÊNCIAS}

ADORNO, Theodor W.; HORKHEIMER, Max. Dialética do esclarecimento: fragmentos filosóficos. Rio de Janeiro: Jorge Zahar, 1985.

ALMEIDA, Ana Carolina Neto de et al. Corpo estética e obesidades: Reflexões baseadas no paradigma da Indústria Cultural. Estudos, Goiânia, v. 33, n. 9/10, p. 789-812, 2006.

ARAÚJO, Denise Castílio de. Corpo feminino: Construção da mídia? Revista Digital, Buenos Aires, ano 13, n. 120, maio 2008. Disponível em: < http:// www.efdeportes.com/efd120/corpofeminino-construcao-da-midia.htm > . Acesso em: 19 dez. 2009.

BAPTISTA, Tadeu João Ribeiro. Educação do corpo na sociedade do capital. Curitiba: Appris, 2013.

BAPTISTA, Tadeu João Ribeiro. Procurando o lado escuro da Lua: implicações sociais da prática de atividades corporais realizadas por adultos em academias de ginástica de Goiânia. Dissertação (Mestrado em Educação Brasileira) Universidade Federal de Goiás, Goiânia, 2001.

BAPTISTA, Tadeu J. R.; ARAÚJO, Danuza R. de; BRITO, Jaqueline C. de. Belíssima ou Beleza Pura: Novela e modelo de Beleza feminina. Estudos, Goiânia, v. 36, n. 9/10, p. 1073-1089, 2009.

BEZERRA, Laise Tavares Padilha. A dança dos monstros corpo e estética na arte e na Educação Física. Dissertação (Mestrado em Educação), Universidade Federal do Rio Grande do Norte, Rio Grande do Norte, 2008.

DAMICO, José Geraldo Soares; MEYER, Dagmar Estermann. O Corpo como marcador social: saúde, beleza e valorização de cuidados corporais de jovens mulheres. Revista Brasileira de Ciências do Esporte, Campinas, v. 27, n. 3, p. 103-118, maio 2006.

DUBY, George. História da vida privada. v. 5. São Paulo: Edições Afrontamento, 1991.

GOELLNER, Silvana V. A produção cultural do corpo. In: LOURO, Guacira L.; FELIPE, Jane; GOELLNER, Silvana V. (org.). Corpo, Gênero e Sexualidade: um debate contemporâneo na educação. 2 ed. Petrópolis: Vozes, 2003, p. 28-40. LOVISOLO, Hugo. Em defesa do modelo JUBESA (Juventude, Beleza e Saúde). In: BAGRICHEVSKY, Marcos; PALMA, Alexandre; ESTEVÃO, Adriana (Org.). A Saúde em Debate na Educação Física. v. 2. Blumenau: Nova Letra, 2006, p. 156-175.

LUKÁCS, Georg. História e Consciência de Classe: estudos sobre a dialética marxista. São Paulo: Martins Fontes, 2003.

MARX, Karl. O Capital: crítica da economia política. 29. ed. Rio de Janeiro: Civilização Brasileira, 2011, livro 1, v. 1. MEYER, Dagmar E. Gênero e educação: teoria e política. In: LOURO, Guacira L.; 
FELIPE, Jane; GOELLNER, Silvana V. (org). Corpo, Gênero e Sexualidade: um debate contemporâneo na educação. 2 ed. Petrópolis: Vozes 2003, p. 09-27. NEPOMUCENO, Marília. O Corpo na Dança: uma Reflexão a partir dos olhares da Indústria Cultural. Pensar a Prática, Goiânia, v. 13, n. 1, p. 119, jan./abr. 2010.

NÓBREGA, Terezinha Petrucia da. Agenciamentos do corpo na sociedade contemporânea: uma abordagem estética do conhecimento da Educação Física. Motrivivência, Santa Catarina, v. 12, n. 16, p. 53-68, mar. 2001.

ROSA, Maria das Dores da. Juventude eterna e "ditadura" do corpo perfeito os discursos da mídia e as práticas da beleza feminina de 1990 a 2005 . Monografia (Bacharelado em História), Universidade do Estado de Santa Catarina, Florianópolis, 2005.

SILVA, Ana Márcia. Corpo Ciência e Mercado. Campinas, SP: Autores associados, 2001. SILVA, Angélica Teixeira da; SILVA, Ana Márcia; BAPTISTA, Tadeu João Ribeiro. Corpo e saúde a "flor da pele": reflexões acerca da concepção de professores de Educação Física. Investigacion y Educacion Física, Argentina, v. 1, n. 1. p. 01-17, jun. 2012.

VIGARELLO, Georges. História da Beleza: O corpo e a arte de se embelezar, do Renascimento aos dias de hoje. Rio de Janeiro, RJ: Ediouro, 2006.

RELATIONSHIPS BETWEEN WOMEN BEAUTY AND HEALTH: a look from female teachers of Physical Education perspective

\begin{abstract}
This descriptive qualitative research aimed to discuss possible Culture Industry Influences, as well as the actual consumption logic into the relationships between woman beauty and health from a study realized with 20 female physical education teachers of Goiania/GO public schools. Their information indicate the approach between beauty and health concepts and marks of a fetishization and reification historic process of women body. However, it is perceived movements of contradiction and resistance to the imposed standards.
\end{abstract}

Keywords: Body; Beatuy; Healt; Woman; Culture Industry 
V. $26, n^{\circ} 43$, dezembro/2014

RELACIONES ENTRE BELLEZA Y SALUD FEMENINA: una mirada a partir de la perspectiva de profesoras de Educación Física

\section{RESUMEN}

Investigación cualitativa del tipo descriptiva objetivó discutir posibles influencias de la Industria Cultural, así como de la actual lógica de consumo en las relaciones entre belleza y salud femenina a partir de investigación realizada con 20 profesoras de Educación Física de la red pública de enseñanza de Goiânia/GO. Los datos indican una aproximación entre los conceptos de belleza y salud y marcas de un proceso histórico del fetiche y reificación del cuerpo femenino. Es posible percibir, sin embargo, movimientos de contradicción y resistencia a los patrones impuestos.

Palabras clave: Cuerpo; Belleza; Salud; Mujer; Industria Cultural

Recebido em: abril/2014 Aprovado em: junho/2014 